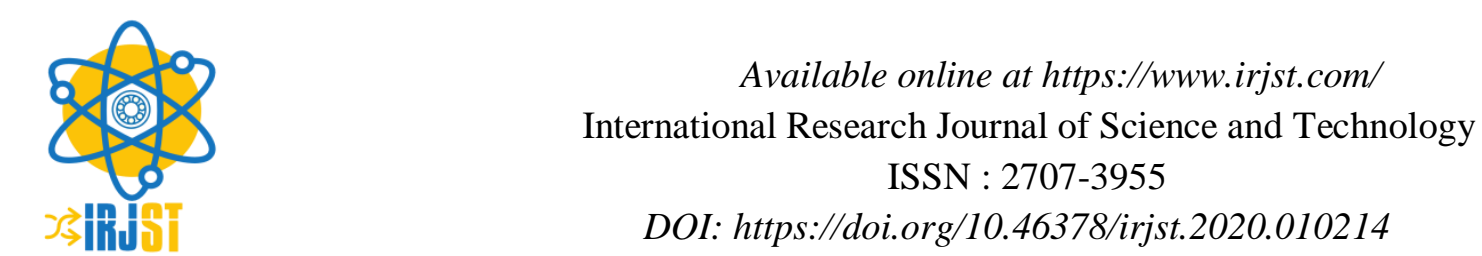

\title{
Review on the Production and Characterization of Glucose and Ethanol from Sugarcane Bagasse.
}

\author{
Majur Mading Makur ${ }^{1,2}$ and Tewodros Birhanu ${ }^{2}$ \\ ${ }^{1}$ Department of Chemistry, College of Education, University of Bahr El Ghazal-Wau, the Republic of South Sudan \\ ${ }^{2}$ Department of Chemistry, Arba Minch University, Arba Minch, Ethiopia.
}

\section{Paper Status \\ Received : Feb 2020 \\ Accepted : Mar2020 \\ Published : Mar 2020}

Key Words

Bagasse

Fermentation

Pretreatment

\section{Abstract}

It was estimated that crude oil production will begin to decline before 2010 from 25 to 5 billion in 2050. Many countries are depending on fossil fuel that causes shortage. Therefore, there is great need to explore the alternative means of fuel production from bagasse. The aim of the present paper is the production of low-cost simple sugars and ethanol from sugarcane bagasse. The paper provides important guidelines on how to produce sugars and ethanol from sugarcane bagasse. It also helps in determining the cheapest method, risk involve in process and chemicals applied. Sugarcane bagasse was pretreated by four different methods such as physico-chemical, chemical, biological pretreatments and hydrolysis. The processes of alkaline, dilute acid pretreatment $(\mathrm{NaOH})$ and enzymatic hydrolysis were found to be the best for production of sugars while simultaneous saccharification and fermentation (SSF) for ethanol production.

Copyright (C) 2020: Majur Mading Makur and Tewodros Birhanu. This is an open access distribution, and reproduction in any medium, provided Access article distributed under the Creative Commons Attribution License the original work is properly cited License, which permits unrestricted use.

Citation: Majur Mading Makur and Tewodros Birhanu. "Review on the Production and Characterization of Glucose and Ethanol from Sugarcane Bagasse”. International Research Journal of Science and Technology, 1 (2), 169-176, 2020.

\section{Introduction}

Fossil fuels provide the single largest fraction of the world's energy, accounting for about $37 \%$ of the total world energy used for fuel from petroleum [1]. It is used for transportation and generation of other energies, which is almost dependent on petroleum, particularly for powering personal vehicles and trucks. This dependency on oil has contributed to global warming, pollution and importing oil creates a dependency on oil producing countries [2]. It was estimated that crude oil production will begin to decline before 2010 from 25 to 5 billion in 2050 . Because many nations' economy depends on oil, the consequences of inadequate oil availability could be severe [3]. Bio-fuels are being investigated as potential substitutes for current high pollutant fuels obtained from Conventional sources.

\footnotetext{
${ }^{*}$ Corresponding author: Majur Mading Makur

Department of Chemistry, College of Education, University of

Bahr El Ghazal-Wau, the Republic of South Sudan

Email: meelchaam@yahoo.com, meelchaam@gmail.com
}

The quest for alternative energies has provided many ways to produce electricity, such as wind farms, hydropower, or solar cells [4].

Sugarcane or its scientific name Saccharum officinarum is one type of the lignocellulosic biomass, which is abundant and can be easily found. The solid residue left after extraction of the juice is called sugarcane bagasse or generally called as bagasse. Bagasse is the fibrous and dry pulpy matter that remains after sugarcane stalks are crushed to extract their juice. Sugarcane bagasse, previously considered a waste and it is one of the most abundant co-products in the sugar and ethanol industries [5]. About $50 \%$ of bagasse is burned to be used as a fuel for combined heat and power systems implemented to meet energy needs of the mills and the remainder is stored, for the manufacture of pulp and building materials [6]. Bagasse generally contains lignin, hemicelluloses and celluloses. Lignin can be hydrolyzed into polyaromatic hydrophobic structure for renewable solid fuel, while hemicelluloses can be hydrolyzed into five carbon $\left(\mathrm{C}_{5}\right)$ sugars for bio-refineries or enzymes production [7]. Sugar as a source of energy is produced from sugarcane bagasse by four ways. The first one is the 
physico-chemical pretreatment of the bagasse, second one is the chemical, thirdly is hydrolysis and the fourth is biological pretreatment. Many pretreatment methods have been reported and several detailed review papers have been published. The pretreatment process indicates positive impact on the cellulose hydrolysis and consequently the sugars' yield. The pretreatment is initiated to separate lignin and hemicelluloses from cellulose, reduce cellulose crystallinity and increase the porosity of the lignocellulosic materials so that cellulose hydrolysis can be improved [8].

Cellulose can be hydrolyzed into sugars using enzymes under certain conditions like temperature, $\mathrm{pH}$, and time, quantity of cellulose and concentration of enzyme. This could be optimized by a response Surface methodology to good data and glucose can be converted into fructose from sugarcane bagasse as an alternative way [9]. As the competition for nonrenewable fossil fuels is rising, alternative energy sources such as ethanol, which is produced by fermentation of sugars from biomass residues, should be decided. However, the cost of ethanol as an energy source is relatively high compared to fossil fuels [10]. The present paper describes the production of simple sugars and ethanol from sugarcane bagasse. The other important parameter is to determine the pretreatment methods with few steps which are environmentally friendly.

\section{Production Methods}

The process of production was categorized into first the pretreatment of bagasse to obtain sugars and finally fermentation to produce ethanol.

\subsection{Production of Sugars from bagasse}

Sugar was first isolated from raisin in 1747 by French scientist Andrea Marggraf. The name glucose for example was driven by the French from the Greek word $\gamma \lambda v \kappa o ́ s$, meaning "sweet". The suffix "-ose" is a chemical classifier, denoting a carbohydrate [11].Glucose extracted from corn is dextrose and they are identical biochemically with a formula $\mathbf{C}_{6} \mathbf{H}_{12} \mathbf{O}_{6}$. It appears to be present in sugarcane bagasse and grain stalk bagasse. There are various different sugars obtained by different methods.

\subsubsection{Pretreatment of Lignocellulosic Materials}

Before the enzymatic hydrolysis is performed, the bagasse must be pretreated first to improve its digestibility and easy access for microbial attack [12]. The pretreatment process involves employing high temperature, pressure, acids or alkaline and organic solvents to disrupt the lignin seal and the cellulose crystalline structure of lignocellulosic material. There are four methods of pretreatments such as physicochemical, chemical, biological pretreatments and hydrolysis.

\section{a. Physico-Chemical Pretreatment}

\section{i. Steam explosion (autohydrolysis)}

Steam explosion is the most commonly used method for pretreatment of lignocellulosic materials. In this method, chipped biomass is treated with high pressure saturated steam and then the pressure is swiftly reduced, which makes the materials undergo an explosive decompression. Steam explosion is carried out at a temperature of $160-260{ }^{\circ} \mathrm{C}$ for several seconds to a few minutes before the material is exposed to atmospheric pressure. The process causes hemicellulose degradation and lignin transformation due to high temperature, thus increasing the potential of cellulose hydrolysis [13].

Steam explosion pretreatment is affected by residence time, temperature, chip size and moisture content. The addition of $\mathrm{H}_{2} \mathrm{SO}_{4}$ (or $\mathrm{SO}_{2}$ ) or $\mathrm{CO}_{2}$ in steam explosion can effectively improve enzymatic hydrolysis, decrease the production of inhibitory compounds, and lead to more complete removal of hemicellulose. Steam explosion pretreatment requires low energy compared to mechanical comminution cheap process for hardwoods and agro residues, but less effective for softwoods. Steam explosion may destroy the xylan, incomplete disruption of the lignin, and generation of compounds that may inhibit microorganisms used in downstream processes. The water wash decreases the saccharification yields due to the removal of soluble sugars, such as those generated by hydrolysis of hemicellulose.

\section{ii. AFEX (Ammonium Fiber Expansion)}

AFEX is similar to the steam explosion method. In AFEX pretreatment, the biomass is exposed to hot liquid ammonia under high pressure and a moderate temperature $\left(60-100{ }^{\circ} \mathrm{C}\right)$ for a period of time, and the pressure is suddenly released.

The reduction of pressure opens up the structure of lignocellulose containing biomass, leading to the increased digestibility of the biomass. AFEX includes an aqueous ammonia dosage, $(1-2 \mathrm{~kg}$ ammonia/kg dry biomass), temperature of less than $90^{\circ} \mathrm{C}, \mathrm{pH}$ of less than 12.0 and a pretreatment time of about 30 minutes or less. AFEX has been used in the pretreatment of various lignocellulosic materials, including rice straw, municipal solid waste, newspaper, sugar beet pulp, sugarcane bagasse, corn stover and switch grass [14]. 


\section{b. Chemical Pretreatment}

\section{i. Ozonolysis}

Ozone can be used to degrade lignin and hemicellulose in many lignocellulosic materials such as wheat straw, bagasse, green hay, peanut, pine, cotton straw, and poplar sawdust. The degradation was essentially limited to lignin and hemicellulose which were slightly attacked, but cellulose was hardly affected.

Enzymatic hydrolysis yield increased while the percentage of lignin decreased after ozonolysis pretreatment of sugarcane bagasse. Ozonolysis pretreatment removes effectively lignin, nontoxic residues and it is carried out at room temperature and pressure. Ozonolysis requires a large amount of ozone, making the process expensive [15].

\section{ii. $\mathrm{CO}_{2}$ explosion}

$\mathrm{CO}_{2}$ explosion is also used for pretreatment of lignocellulosic materials. It was hypothesized that $\mathrm{CO}_{2}$ would form carbonic acid and increase the hydrolysis rate. Pretreatment was used in alfalfa by researchers and they obtained $75 \%$ of the theoretical glucose released during 24 hours of the enzymatic hydrolysis. The yields were relatively low compared to steam or ammonia explosion pretreatment, but high compared to the enzymatic hydrolysis pretreatment. It was compared with steam and ammonia explosion for pretreatment of recycled paper mix, sugarcane bagasse, and found that $\mathrm{CO}_{2}$ explosion was more cost effective than ammonia explosion but it did not cause the formation of inhibitory compounds.

\section{iii. Acid Pretreatment}

Acids such as $\mathrm{H}_{2} \mathrm{SO}_{4}$ and $\mathrm{HCl}$ have been used to treat lignocellulosic materials, although they are powerful agents for cellulose hydrolysis, the acids are toxic, corrosive and hazardous and require reactors that are resistant to corrosion. The concentrated acid must be recovered after hydrolysis to make the process economically feasible [16]. The dilute sulfuric acid pretreatment can achieve high reaction rates and significantly improve cellulose hydrolysis. At moderate temperature, direct saccharification suffered from low yields because of sugar decomposition. High temperature in dilute acid treatment is favorable for cellulose hydrolysis though it's costly than some physico-chemical pretreatment processes such as AFEX. A neutralization of $\mathrm{pH}$ is necessary for the downstream enzymatic hydrolysis or fermentation processes.

\section{iv. Alkaline Pretreatment}

Bases such as sodium, calcium, potassium, and ammonium hydroxides can be used for pretreatment of lignocellulosic materials; this depends on the lignin content of the materials. The mechanism of alkaline hydrolysis is saponification of intermolecular ester bonds cross linking xylan hemicelluloses and other components such as lignin and other hemicellulose. The porosity of the lignocellulosic materials increases with the removal of the cross-links. Dilute $\mathrm{NaOH}$ treatment of lignocellulosic materials caused swelling, leading to an increase in internal surface area, a decrease in the degree of polymerization, a decrease in crystallinity, separation of structural linkages between lignin and carbohydrates, and disruption of the lignin structure. There is no effect of dilute $\mathrm{NaOH}$ pretreatment was observed for softwoods with lignin content greater than $26 \%$. Dilute $\mathrm{NaOH}$ pretreatment was also effective for the hydrolysis of straws with relatively low lignin content of $10-18 \%$.

Ammonia was also used for the pretreatment to remove lignin from corn cobs and switch grass.

\section{v. Oxidative delignification}

Lignin biodegradation could be catalyzed by the peroxidase enzyme with the presence of $\mathrm{H}_{2} \mathrm{O}_{2}$. The hydrogen peroxide greatly enhanced bagasse susceptibility to enzymatic hydrolysis. About 50\% lignin and most hemicellulose were solubilized by $2 \%$ $\mathrm{H}_{2} \mathrm{O}_{2}$, and $95 \%$ efficiency of glucose production from cellulose was achieved in the saccharification by cellulase. Developers used wet oxidation and alkaline hydrolysis of wheat straw, and achieved 85\% conversion yield of cellulose to glucose.

\section{vi. Organosolv process}

Organosolv pretreatment is a pulping technique that dissolves lignin and hemicellulose in an organic solvent while cellulose remains as undissolved solids. Catalysts such as organic or aqueous organic solvent mixture $\left(\mathrm{HCl}\right.$ or $\left.\mathrm{H}_{2} \mathrm{SO}_{4}\right)$ with inorganic acid catalysts are used to break the internal lignin and hemicellulose bonds in the process. Organic acids such as oxalic, acetylsalicylic and salicylic can also be used as catalysts in the organosolv process. The organic solvents used in the process most commonly are methanol and ethanol because of low cost. At high temperatures (above $185^{\circ} \mathrm{C}$ ), the addition of catalyst was unnecessary for satisfactory delignification. Usually, a high yield of xylose can be obtained with the addition of acid. Solvents used in the process need to be drained from the reactor, evaporated, condensed and recycled to reduce the cost. Removal of solvents from the system is necessary because the solvents may be inhibitory to the growth of organisms, enzymatic hydrolysis, and fermentation. The organosolv method is used with all types of feedstock, but it involves high operation cost and high cost organic solvents. 


\section{c. Biological pretreatment}

In biological pretreatment processes, microorganisms such as brown, white and soft rot fungi are used to degrade lignin and hemicellulose in waste materials such as bagasse. Brown rots attacks cellulose, while white and soft rots attack both cellulose and lignin. White-rot fungi are the most effective basidiomycetes for biological pretreatment of lignocellulosic materials [17].

Both enzymes have been found in the extracellular filtrates of many white-rot fungi for the degradation of wood cell walls. Biological pretreatment requires low energy and mild environmental conditions. However, the rate of hydrolysis in most biological pretreatment processes is very low.

\section{d. Hydrolysis of Lignocellulosic Material}

The cellulose molecules are composed of long chains of sugar molecules. In the hydrolysis process, these chains are broken down to "free" the sugar, before it is fermented for alcohol production. There are two major hydrolysis methods:

\section{i. Acidic hydrolysis}

Acidic hydrolysis has been investigated as a possible process for treating lignocellulosic materials such as wood chips, rice straw, sugar beet pulp and wheat straw [18]. The mineral acids act simply as reaction catalyzers of polysaccharide fractions. Sugarcane bagasse can be hydrolyzed using dilute acid to obtain a mixture of sugars with xylose as the major component. The pretreatment involves hydrochloric acid, phosphoric acid, nitric acid and sulphuric acid to produce xylose and glucose. Treatment with dilute sulphuric acid at moderate temperatures has an efficient means of producing xylose from hemicellulose. Proper combinations of $\mathrm{pH}$, temperature, and reaction time can result in high yields of sugars, primarily xylose from hemicellulose in presence of Sulphuric acid as catalyst [19].

\subsection{Production of ethanol}

Ethanol is produced from the pretreated sugarcane bagasse by the process of fermentation. There are number of fermentation methods reported as detailed below.

\subsubsection{Fermentation process}

A variety of microorganisms such as bacteria, yeast, or fungi, ferment carbohydrates to ethanol under oxygenfree conditions to obtain energy for growth. According to the reactions for the theoretical maximum yield, ethanol and carbon dioxide are released.

$3 \mathrm{C}_{5} \mathrm{H}_{10} \mathrm{O}_{5} \longrightarrow$ Enzyme $\longrightarrow 5 \mathrm{C}_{2} \mathrm{H}_{5} \mathrm{OH}+5 \mathrm{CO}_{2}(1)$

\section{ii. Enzymatic Hydrolysis}

Pretreatment is important in transforming lignocellulose into monomeric sugars that can be consumed by microorganisms during alcohol fermentation process [20]. Enzymatic hydrolysis is done on solid residues stream from the pretreatment process, although there are some exceptions where the whole pretreatment slurry is enzymatically hydrolyzed [21].

Enzymatic hydrolysis is affected by temperature, enzyme type and loadings, as well as hydrolysis time. Enzymatic hydrolysis takes place at temperatures around $45{ }^{\circ} \mathrm{C}$ to $50{ }^{\circ} \mathrm{C}$ and it has been found to be optimum for most of the cellulases [22]. Some researchers have found that increasing enzyme loading had significant increase in hydrolysis sugars yield. For example, enzyme loading between 650 - 1300 FPU/L for hydrolysis of cow manure fiber varied. Hence, enzyme loading is a parameter that requires to be taken into account in order to achieve high hydrolysis yields [23].

\subsubsection{PH adjustment of hydrolysate}

Hydrolysis is of many types; dilute acid hydrolysis is an easy and productive process which produces concentrated acid. They are hazardous and corrosive process and also acid has to be separated out after hydrolysis for feasibility. The $\mathrm{pH}$ of these samples has to be adjusted to avoid death of micro-organism in hyper acidic or basic state. A pH of around 5-5.5 is maintained.

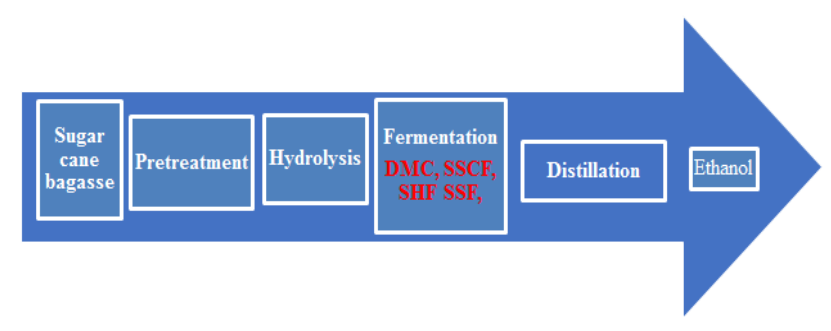

Chart 1. Generalized steps of ethanol production

$\mathrm{C}_{6} \mathrm{H}_{12} \mathrm{O}_{6} \longrightarrow 2 \mathrm{C}_{2} \mathrm{H}_{5} \mathrm{OH}+2 \mathrm{CO}_{2}$ (2)

Methods for $\mathrm{C} 6$ sugar fermentation were already known 6000 years ago, when Sumerians, Babylonians and Egyptians began to perfect and describe the process of making beer from grain (starch). After it became possible to free the $\mathrm{C}_{6}$ sugars in lignocellulosic crops (end $19^{\text {th }}$ century), conversion of the $\mathrm{C}_{5}$ sugars became interesting. They represent a high percentage of the available sugars, the ability to recover and ferment them into ethanol is important for the efficiency and economics of the process. Only in the 1980s, research on xylose fermentation began to bear fruit, when a number of wild type yeast were identified 
that could convert xylose to ethanol. Hexoses such as glucose, galactose and mannose are readily fermented to ethanol by various microorganisms however pentose sugars such as xylose, arabinose are fermented only by few native strains that typically have very low yields. In order to make the economics of cellulosic ethanol production possible, it is essential to utilize the pentose sugars.

\subsubsection{Methods used for the fermentation process}

\section{i. Direct microbial conversion (DMC)}

Lignocellulosic biomass can be directly converted into ethanol using microorganisms that have the potential to delignify the biomass and convert the resulting cellulose into ethanol, usually using co-cultures of different microbial strains. Direct microbial conversion combines cellulose production, hydrolysis and fermentation into a single step [24]. This is accomplished in two ways, namely a solid-state fermentation process (microbiological) and a liquid state fermentation process (submerged fermentation) which is carried out in dilute solutions or slurries. Microorganisms that can hydrolyze cellulose and ferment the produced sugar components rapidly and efficiently do not occur naturally. The operation cost is low since only one reactor is needed and no chemicals are added. However, the ethanol yield is low and the organisms used usually have low ethanol tolerance [25]. However, it is not easy to protect the environment.

\section{ii.Simultaneous saccharification and co- fermentation (SSCF)}

The simultaneous saccharification and co-fermentation (SSCF) method is an improved version of the SSF technology [26]. This method is based on the cofermentation of hexose and pentose sugars. The SSCF is carried out by genetically engineered microbes that ferment xylose and glucose in the same process unit concurrently with the enzymatic hydrolysis of cellulose and hemicellulose. The SSCF process can only be accomplished by inserting genes that either encodes the production of xylose reductase (XR) and xylitol dehydrogenase (XDH) or the xylose isomerase (XI) into industrial strains such as $\mathrm{S}$. cerevisiae [27]. These enzymes enable S. cerevisiae to also ferment xylose to bioethanol using different pathways, where xylose is first isomerized to xylulose prior to fermentation.

\section{iii. Separate hydrolysis and fermentation (SHF)}

Separate hydrolysis and fermentation (SHF) method is a process whereby a sequential route is employed. The solid fraction of the pre-treated lignocellulosic biomass, which mainly contains cellulose, is enzymatically hydrolyzed and the resulting hydrolysate is then fermented to ethanol in a separate step [28]. The advantage of the SHF process is that each step can be performed at its optimal operating conditions, hence promoting complete hydrolysis of cellulose.

\section{iv. Simultaneous saccharification and fermentation (SSF)}

Bioprocessing of agro-industrial residues in SSF has often been found very efficient. There has been a wide-spread resurgence of SSF all over the world due to several advantages it offers, mainly on engineering aspects numerous SSF processes have been developed in which bagasse has been used as the solid substrate. Bagasse is used for the production of protein-enriched animal feed by SSF, employing yeasts and fungi. Scientists have found varying degrees of degradation by white-rot fungi and also variation in vitro cultivation of a fungal strain of Streptomyces, which resulted in $45 \%$ depletion of lignocelluloses.

Cellulase enzymes most extensively used in SSF of bagasse. The hydrolysis of the lignocellulosic residues, using enzymes largely depends upon the cost of the production of cellulases [29]. SSF is an integral process for the production of ethanol, furfural, and mixture of bagasse and wheat bran which is used for the production of cellulases.

\section{v. Distillation}

Distillation is the last step in the production of ethanol from bagasse experiments. It is the purification step. Distillation is the method used to separate two liquid based on their different boiling points. However, to achieve high purification, several distillations are required [30].

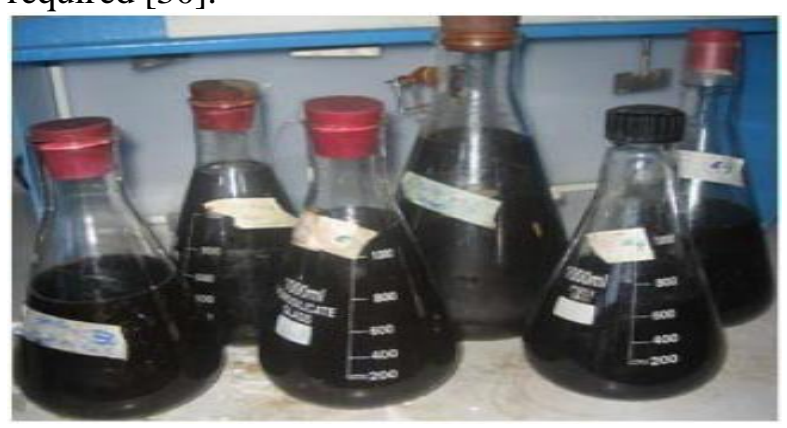

Fig 1. Distilled ethanol[30].

\section{Characterization}

\subsection{Determination of Sugars' Concentration Using DNS Reagent}

The DNS method is used for estimating the concentration of reducing sugars in a sample [31]. Reducing sugars have the property to reduce many of the reagents. A reducing sugar is one that in a basic solution forms an aldehyde, carbonyl group or ketone. The aldehyde group of sugars converts 3,5- 
dinitrosalicylic acid (DNS) to 3-amino-5-nitrosalicylic acid, which is the reduced form of DNS. Water is used up as a reactant and oxygen gas is released during the reaction. The formation of 3-amino-5-nitrosalicylic acid results in a change in the amount of UVspectrophotometer's light, at wavelength of $540 \mathrm{~nm}$. This determination can lead to the calculations below.

$$
\begin{aligned}
& \begin{array}{c}
\text { Sugar }(\mathrm{g}) \\
\text { Global yield }(\mathrm{g})=\text { Solid fraction } \mathrm{x} \ldots \ldots \ldots \ldots \ldots \ldots \ldots \ldots \ldots \ldots \ldots \ldots \ldots \ldots \ldots \ldots \ldots \ldots \ldots \ldots \ldots \\
\text { Initial amount of pretreated bagasse }(\mathrm{g})
\end{array}
\end{aligned}
$$

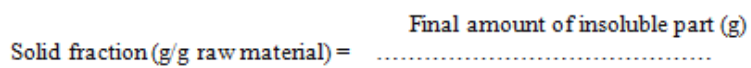

$$
\begin{aligned}
& \text { Initial amount of raw material(g) }
\end{aligned}
$$

Table 1. Summary of fermentation process with advantages and disadvantages

\begin{tabular}{|c|c|c|}
\hline Process & Advantages & Disadvantages \\
\hline DMC & $\begin{array}{l}\text { Requires one } \\
\text { reactor. } \\
\text { Cost effective. }\end{array}$ & $\begin{array}{l}\text { Very slow. } \\
\text { It is not easy to achieve a } \\
\text { natural habitat in a } \\
\text { laboratory setting. }\end{array}$ \\
\hline SHF & $\begin{array}{l}\text { Operates at optimal } \\
\text { conditions. }\end{array}$ & $\begin{array}{l}\text { End product inhibition. } \\
\text { Lower yields. }\end{array}$ \\
\hline SSF & $\begin{array}{l}\text { Higher ethanol } \\
\text { yields due to } \\
\text { increased } \\
\text { hydrolysis rate. } \\
\text { Shorter process } \\
\text { time. }\end{array}$ & $\begin{array}{l}\text { Non-optimal process } \\
\text { conditions }\end{array}$ \\
\hline SSCF & $\begin{array}{l}\text { Ferments both } \\
\text { hexose and pentose } \\
\text { sugars. }\end{array}$ & $\begin{array}{l}\text { Requires genetically } \\
\text { engineered microbial } \\
\text { strains. }\end{array}$ \\
\hline
\end{tabular}

\subsection{Determination of sugar conversion}

The amounts of sugars, HMF, furfural and organic acids were obtained by HPLC at $65^{\circ} \mathrm{C}$, sulfuric acid in MilliQ water as eluent, a flow rate of $0.6 \mathrm{~mL} / \mathrm{min}$ and a refraction index detector. The amount of digested cellulose was determined according to the NREL digestibility protocol of lignocellulosic biomass subjected to pretreatments according to Equations [32].

$$
\begin{aligned}
& \text { Digested cellulose }(\mathrm{g}) \\
(\%) \text { Conversion }= & \ldots \ldots \ldots \ldots \ldots \ldots \ldots \ldots \ldots \ldots \ldots \ldots \ldots \ldots \ldots \\
& \text { Added cellulose }(\mathrm{g})
\end{aligned}
$$

Digested cellulose $(\mathrm{g})=$ (Reaction volume $(1) \quad \mathrm{x}$ (Glucose $(\mathrm{g} / \mathrm{l})) \times 0.9+$ Cellulose $(\mathrm{g} / \mathrm{l}) \times 0.9$

\subsection{Composition of Sugarcane Bagasse}

The sugarcane bagasse is composed of Cellulose (glucan and xylan), hemicellulose, lignin, ash and organic solvent extractives in the solid fraction of the untreated and pretreated bagasse. The amounts of cellulose, hemicellulose, lignin and ashes were determined by high pressure liquid chromatography
(HPLC) [33]. Scanning electron microscopy (SEM) was used to observe the morphology of the raw and pretreated bagasse to evaluate the changes in the external structure using a voltage of $20 \mathrm{kV}$ and working distance of $10 \mathrm{~mm}$, spot size of 4.0 , detector and metallizer.

FTIR (Fourier transform infrared) analysis was used to detect the presence of the main organic groups that constitute the lignocellulosic structure.

This analysis allowed the detection of the amorphous part of the lignocellulosic biomass, as well as the modification of the crystalline structure of the cellulose. The crystallinity index (CI) was obtained from the ratio of the maximum peak intensity $002\left(\mathrm{I}_{002}\right.$, $2 \theta=22.5$ ) and minimal depression (Iam $2 \theta=18.5$ ) between peaks 001 and 002 [34] were obtained according to Equation (1) below.

$$
\begin{aligned}
& I_{002}-I_{a m} \\
& \mathrm{CI} \%=\ldots \ldots \ldots \ldots \ldots \ldots \ldots \ldots 100 \\
& \mathrm{I}_{\mathrm{am}}
\end{aligned}
$$

Where $\mathrm{I}_{002}$ is the maximum intensity of the 002 peak and $I_{a m}$ the minimal depression of the amorphous structure.

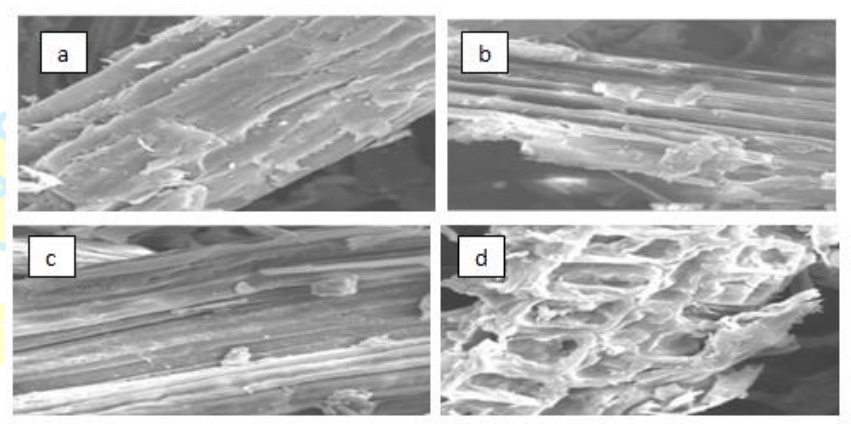

Fig 2. Morphology of the bagasse after and before the pretreatment processes by SEM (a. Natural bagasse. b. Dilute $\mathrm{H} 2 \mathrm{SO} 4$ pretreated c. $\mathrm{NaOH}$ pretreated d. Enzyme hydrolyze [34].

\section{Conclusion}

The processes of alkaline, dilute acid pretreatments and enzymatic hydrolysis were the most preparation methods to produce simple sugars that are converted into ethanol. The use of alkaline and dilute acid pretreatment is better since a second pretreatment step is not required and a smaller number of reagents are required which can reduce the production of wastes. Enzymatic hydrolysis was reported in many literatures with a higher yield of simple sugars unlike other methods of pretreatment. It has also potential to improve sugar yields at low costs, thus making the process economically viable.

The SSF process, though it does not utilize all the available sugars, is still regarded as the suitable method, since it produces a higher ethanol yield. Additionally, SSF is not affected by end product 
inhibition and does not require genetically engineered microbial strains which are difficult to work with due to their instability. The production of bioethanol from lignocellulosic biomass depends on the progress of improving each process unit, thus obtaining the yield of the product at an affordable cost.

\section{Acknowledgement}

The authors acknowledge the department of chemistry, University of Bahr El Ghazal and Arba Minch University, Ethiopia for the productive directives in this review.

\section{References}

1. Dantas,G.V., Legey, L.F.L \&Mazone, A. 2013. Energy from Sugarcane biogas in Barzil: An assessment of the productivity and cost of different technological routes. Renewable \& sustainable energy reviews 21(0), 356-364, DOI: 10.1016/j.rser.2012.11.080.

2. Olsson L., Hahn-Hägerdal B., 1996. Fermentation of lignocellulosic hydrolysates for ethanol production, Enzyme and Microbial Technology, $18,312-331$

3. Amiri H., Karimi K., 2013. Efficient Dilute-Acid Hydrolysis of Cellulose Using Solvent Pretreatment, Industrial \& Engineering Chemistry Research, 52, 11494-11501.

4. Rabelo S.C., Carrere H., MacielFilho R., Costa A.C., 2011. Production of bioethanol, methane and heat from sugarcane bagasse in a bio refinery concept, Bio resource Technology, 102, 78877895 .

5. McMurry, John. Organic Chemistry. 7th ed. Belmont, CA: Thomson Brooks/Cole, 2008. InPigman and Horton. The Carbohydrates: Chemistry and Biochemistry Vol 1A (2nd ed.). San Diego: Academic Press. pp. 165-194.

6. Encyclopedia of Food and Health. Academic Press. 2015. p. 239. ISBN 9780123849533.

7. Pandey, A.; Soccol, C. R.; Nigam, P.; Soccol, V. T.; Vandenberghe, L. P. S.; Mohan, R., 2000. Biotechnological potential of agro-industrial residues. II: cassava bagasse. Bioresource Technol., 74 (1): 81-87.

8. Li, C., Yoshimoto, M., Tsukuda, N., Fukunaga, K., Nakao, K., 2004. A kinetic study on enzymatic hydrolysis of a variety of pulps for its enhancement with continuous ultrasonic irradiation. Biochem. Bioeng. J., 19, 155-

9. Wyman, C.E., 2005. Comparative sugar recovery data from laboratory scale application of leading pretreatment technologies to corn stover. Bioresource technology, 96:2026.
10. Sun Y, Cheng J., 2002. Hydrolysis of lignocellulosic material for ethanol production: a review. BioresourTechnol 83:1-11.

11. Goldenberg, R.L., Culane, J.F., Iams, J., Romero, R., 2008. Epidemiology and causes of preterm birth. The Lancet, 371: 73-82.

12. Lee H, Jang Y, Choi YS. 2014. Biotechnological procedures to select white rot fungi for the degradation of PAHs. J microbiol methods, 97; 56 $-62$

13. Almeida, A., Produção de ProteínaMicrobiana a partir de hidrolisadohemicelulósico de palha de arroz, 1991. Masters of Science thesis. Universidade Federal de Viçosa

14. Elander, R. and Hsu, T.1995. Processing and Economic Impacts of Biomass Delignification for Ethanol Production. Appl. Biochem Biotechnol, 51/52, 463-

15. Elander, Richard T., Bruce E. Dale, Mark Holtzapple, Michael R. Ladisch, YY Lee, Colin Mitchinson, John N. Saddler, and Charles E. Wyman. 2009. "Summary of Findings from the Biomass Refining Consortium for Applied Fundamentals and Innovation (CAFI): Corn Stover Pretreatment." Cellulose 16 (4): 649 - 659-

16. Humbird, D., R. Davis, L. Tao, C. Kinchin, D. Hsu, and A. Aden. 2011. "Process Design and Economics for Biochemical Conversion of Lignocellulosic Biomass to Ethanol." Contract 303: 275-3000.

17. Lloyd, Todd A. and Charles E. Wyman. 2005. "Combined Sugar Yields for Dilute Sulfuric Acid Pretreatment of Corn Stover Followed by Enzymatic Hydrolysis of the Remaining Solids." Bioresource Technology 96 (18): 1967-1977.

18. Liao, Wei, Z. Wen, S. Hurley, Y. Liu, C. Liu, and S. Chen. 2005. "Effects of Hemicellulose and Lignin on Enzymatic Hydrolysis of Cellulose from Dairy Manure", volume 124. pp 1017 - 1030-

19. Nag, A. 2008. Biofuels refining and performance. McGraw Hill Professional, New York. pp $69-$ 106-

20. Silverstein, R. A. A. 2004. Comparison of chemical pre-treatment methods for converting cotton stalks to ethanol. North Carolina State University, Raleigh, North Carolina [M.Sc. Thesis].

21. Balat, M., Balat, H., and Oz, C. 2008. Progress in bioethanol processing. Progress in Energy and Combustion Science, 34 (5): 551-573.

22. Eliasson, A., Christensson, C., Wahlbom, F., and Hahn-Hägerdal, B. 2000. Anaerobic xylose fermentation by recombinant Saccharomyces cerevisiae carrying XYL1, XYL2, and XKS1in 
mineral medium Chemostat cultures. Applied and Environmental Microbiology, 66 (8):3381-3386.

23. Linde, M., Jakobsson, E., Galbe, M., and Zacchi, G. 2008. Steam pre-treatment of dilute $\mathrm{H}_{2} \mathrm{SO}_{4}-$ impregnated wheat straw and SSF with low yeast and enzyme loadings for bioethanol production. Biomass and Bioenergy, 32: 326 - 332.

24. Wondale Mekonnen. 2012. Production of ethanol from selected fruit peel waste, institute of technology, Addis Ababa University [Msc thesis].

25. Taherzadeh, J.M., and Karimi, K. 2007. Enzymebased hydrolysis processes for ethanol from lignocellulosic materials: A review. BioResources, 2(4), 707-738.

26. Miller, G.L, 1959, Use of dinitrosalicylic acid reagent for determination of reducing sugar, Anal. Chem., 31, 426--

27. Selig, M., Weiss, N., Ji, Y., 2008. Enzymatic Saccharification of Lignocellulosic Biomass, Laboratory Analytical Procedure (LAP). Technical Report, NREL, p. 8

28. Gouveia, E. R., Nascimento, R. T., Souto-Maior, A. M., Rocha, G. J. M., 2009. Validação de metodologiapara a caracterizaçãoquímica de bagaço de canade-açúcar. Quim. Nova, 32, 15001503.

29. Rodrigues, F. G., Assunção, R. M. N., Vieira, J. G., Meireles, C. S., Cerqueira, D. A., Barud, H. S., Ribeiro, S. J. L., Messaddeq, Y., 2007. Characterization of methylcellulose produced from sugarcane bagasse cellulose: Crystallinity and thermal properties. Polym. Degrad. Stab, 92, 205210 . 